This item was submitted to Loughborough's Research Repository by the author.

Items in Figshare are protected by copyright, with all rights reserved, unless otherwise indicated.

\title{
Taking time seriously? Theorizing and researching change in communication and media studies
}

PLEASE CITE THE PUBLISHED VERSION

http://dx.doi.org/10.1111/jcom.12218

\section{PUBLISHER}

John Wiley \& Sons, Inc (@ International Communication Association)

\section{VERSION}

AM (Accepted Manuscript)

\section{PUBLISHER STATEMENT}

This work is made available according to the conditions of the Creative Commons Attribution-NonCommercialNoDerivatives 4.0 International (CC BY-NC-ND 4.0) licence. Full details of this licence are available at: https://creativecommons.org/licenses/by-nc-nd/4.0/

\section{LICENCE}

CC BY-NC-ND 4.0

\section{REPOSITORY RECORD}

Mihelj, Sabina, and James Stanyer. 2016. "Taking Time Seriously? Theorizing and Researching Change in Communication and Media Studies”. Loughborough University. https://hdl.handle.net/2134/20159. 


\section{Taking time seriously? Theorizing and researching change in communication and media studies}

James Stanyer and Sabina Mihelj

\section{Abstract}

Questions of change are of central importance to communication and media research, yet discussions on the temporal nature of change, and the challenges it raises for theorizing and researching communication, have so far remained sporadic and disconnected. This article argues that in order to adequately comprehend and explain change, the field needs to engage more fully with the challenges of researching change over time, and ground the theorizing of change more firmly in empirical research. The goal of this article is to foster a more concerted discussion on these issues that will hopefully move research forward. The first part of the article reviews the breadth and diversity of existing empirical approaches to comprehending change over time across the field. The article then identifies some of the problems and oversights of current approaches and discusses possible solutions, drawing both on proposals developed by communication and media scholars and those developed in other disciplines.

Key words: time, change, communication, media

The field of communication and media research has seen a growing interest in comprehending change over time, as well as the formation of specialist professional associations and journals dedicated to communication history. New overarching theoretical frameworks for understanding change in media and communication have been proposed, including the theory of mediatization and the notion of a new era of minimal effects (Bennett and Iyengar 2008, Lundby 2009). Some authors have also begun considering the specific methodological, conceptual and empirical challenges of researching change over time (e.g., 
Bannerman \& Haggart, 2015, Corner, 2003, Matthes and Schemer, 2012, Ryfe, 2001).

However, such reflective accounts remain sporadic, and have yet to produce a step-change in how we research temporal processes. As a result, much of existing work remains conceptually and methodologically weak, and often proclaims change without demonstrating it empirically, or explaining why it arises. For a field that has traditionally been drawn to the transformative potential of new communication technologies and practices, this is a cause for concern. How can we adequately comprehend the processes that give rise to new developments in communication and media, or investigate their social impact, if we do not have an understanding of the nature of change, and a shared - if contested - set of concepts and methods designed to investigate it?

To advance the debate about researching temporal change, this article starts with an overview of empirical research, and proposes a typology of the main approaches. There have been other attempts to document the state of temporal research in the field (see Ryfe, 2001, 2006; Schulz, 2014) but none as far as we can tell that adopts this approach. We then proceed by subjecting existing approaches to critical scrutiny, highlighting some of the problems and oversights and discussing possible solutions, drawing on ideas from work within and beyond media and communication studies.

\section{Approaches to change in communication: a typology}

The overview provided here is based on a systematic analysis of articles published in three communication and media journals (Journal of Communication; Media, Culture and Society; and Political Communication) over a 15 year period from 2000 to 2014. Although far from comprehensive, this approach provides an effective way to get a good sense of contemporary mainstream approaches in the field, and one more representative than a convenience sample from a potentially vast body of literature. These three journals were chosen because they span the quantitative/ qualitative divide; are seen as leading international journals in the field; and provide a good mix of generalist and specialist research. We are fully aware that a substantial proportion of relevant literature is published in specialist journals and research monographs, especially those dedicated to (communication and media) history, but we felt that this literature is not indicative of the state of the field as a whole, and hence cannot serve as the best basis for the kind of overview we want to provide. 
The review was conducted in two stages. First, we searched the selected journals for articles that made some reference to change over time. Second, we chose articles that conducted empirical research on change over time. These needed to include at least a significant paragraph's worth of discussion of data/ information gathered from two or more points in time. We also looked at articles that focused on methodological or theoretical issues but these were not our main focus; given the frequent disconnect between theorizing and demonstrating change in communication, we were primarily interested in the extent to which a reflective approach to temporal issues is present in empirical research. We do, however, refer to some of the theoretical/methodological pieces we found in our overview of critical issues and solutions.

Our content analysis examined: the subject matter of each study; the time-frame; the methods used; the type of temporal research conducted; any attempts at explanation; and type of analytic method used. The allocation of each article to the various categories was jointly agreed. In total there were 151 articles, of which 142 were research articles, eight focused on theory and one on methodology. This represents only about 1 per cent of all the articles published in the three journals over 15 years. This suggests that temporal issues are not a major preoccupation - a significant finding given the importance of understanding change over time for the field.

Based on this sample we identified three main approaches to researching change over time, which we call: trend mapping; temporal comparison; and turning points. It should be noted that these terms are used for labelling purposes (see Table 1 for what each includes). Each approach was subdivided by thematic focus into production, texts and audiences (Table 1).

[Table 1 about here]

In what follows we expand on each of the three approaches. 
As evident from Table 1, the most common approach was trend mapping, which consists of examining the development of a chosen phenomenon over time, focusing on trends (decline, growth, fluctuations). What is common to all articles in this category is the treatment of time as a continuum, without much attention to periodization. Table 2 shows that the majority examined a period of 29 years or less, with the most popular time span being ten to nineteen years. The analytic level of the research also varied from micro studies of message exposure to macro studies of country media policy. Thematically studies falling into this category focused overwhelmingly on production or on textual change. Most were published in Media Culture and Society and Journal of Communication (see table 1).

[Table 2 about here]

The studies dealing with media production were largely qualitative and mostly focused on media industries $(\mathrm{N}=16)$; nine articles examined specific organizations (e.g., Leye 2009); eight looked at media policy (e.g., D’Arma, 2009); six at media professions (e.g., Volz, 2007); five at national media systems (e.g., Rawan, 2002); four at forms of broadcasting (e.g., Watson, 2002); three at communication systems/ technologies (e.g., Jin, 2008); and three at campaigning practices (e.g. Papathanassopoulos, 2000). These studies often drew on archival and/or interview data, sometimes combined with discourse analysis, and were largely descriptive exercises detailing key changes in the development of the subject of interest.

Trend mapping using textual analysis included: 12 studies of longitudinal changes in the style of media content (e.g., Johnston \& Lee Kaid, 2002); eight articles examining changing discourse (e.g., Coe, Domke, Graham, John, \& Pickard, 2004); six looking at representation in the media (e.g., Hansen, 2006); six at agenda formation (e.g., Atkinson, Lovett \& Baumgartner, 2014); five at the visibility of news actors (e.g., Balmas \& Sheafer, 2013); four focusing on framing (e.g., Callaghan \& Schnell, 2001); and one each on soundbites, bias, emotions and remembrance. These studies were mostly based on quantitative content analyses $(\mathrm{N}=40)$ drawing on successive measurements of the same observational unit over time. 


\section{Forthcoming in Journal of Communication}

This is a pre-print version, submitted in January 2016.

There was a lack of temporal research focusing on audiences with studies that adopted this focus using secondary data sources to explore audience behavior (e.g., Abildgaard, 2014). This deficiency is a characteristic of temporal communication research more generally, although we should acknowledge the recent growth of interest in historical audience research outside of the three journals surveyed here (e.g. Butsch 2000, Mihelj \& Bourdon 2015). Only a very small minority of articles compared spatially as well (e.g., Balmas \& Sheafer, 2013; Groshek, 2011).

As part of the review we also looked for use of temporal concepts in these studies. One that received some attention was mediatization, which was typically used to describe media-related change (see Kepplinger 2002, Peleg \& Bogoch 2012). Many other relevant temporal concepts, such as duration, pace, trajectory and cycles (see Amizande, 1992), were not used in any of the studies.

\section{Temporal comparisons}

Temporal comparisons involve comparing two or more moments in time. These moments can be randomly chosen years, days or months, or particular events (Althaus, Swigger, Chernykh, Hendry, Wals, \& Tiwald, 2014), or the activities of notable individuals (Benoit, Blaney, \& Pier, 2000), or audiences (Glevarec \& Pinet, 2008). In contrast to trend mapping, the concern was less with documenting a trend or the emergence or decline of a phenomenon than with comparing a phenomenon over discreet temporal units of observation. In this context, time was not treated as a continuum but as a succession of units (periods, points in time) with distinct qualities.

The majority of temporal comparative studies examined a time span of 19 years or less. Most focused on changes in texts (broadly defined), comparing anything between two and six points in time (e.g., Benoit, Blaney, \& Pier, 2000; Rojecki, 2009). Six explored changes in media content (e.g., Cho, 2009); four in discourse (e.g., Domke, 2001); and others in the visibility of actors, news frames, representation and news agenda formation.

Studies of audiences were typically two-wave panel studies comparing a range of behavioral and attitudinal responses before and after exposure to known stimuli (there were no cohort studies). For example, Aubrey (2006) used a two-wave panel study two years apart 
to explore the influence of sexually objectifying media images on student's selfobjectification and levels of body surveillance (see also e.g., de Zúñiga, Molyneux, \& Zheng 2014; ). There were some exceptions using other data sources, such as, Ridout , Franz , Goldstein \& Feltus, (2012); Romer, Jamieson, \& Aday, (2003). Studies of production were relatively rare in this category; one example being a study of international film trade in 1996 and 2004 (Chung, 2011).

\section{Turning points}

The third, least common approach concerned identifying turning points or critical junctures; that is moments in time when sudden and lasting change occurs. As Abbott (2001, pp. 243-245) notes, the idea of turning points has a long history in the social sciences, and has been applied extensively in life course research, political science, applied economics and history of science. Within political science, the concept of critical juncture constitutes a key building block of understanding change (Collier \& Collier, 1991) and is particular common among historical institutionalist analysis and the broader New Institutionalism literature, which began attracting some attention among communication researchers (see Bannerman \& Haggart, 2015). However, with exceptions (see Ryfe, 2001, 2006), studies examining turning points in our sample rarely engaged with this broader literature. We found only a few studies that drew on the notion of a critical juncture or some allied concept such as punctuated equilibrium (e.g., Clayman, Elliott, Heritage \& Beckett, 2010, or Coe \& Domke, 2006). Other studies investigating rapid and lasting change, like Mauersberger (2012) and Pickard (2011), did so without reference to these broader discussions. There was little difference between the thematic subdivisions.

\section{Critical issues}

As highlighted earlier, existing work on change in communication often lacks in methodological and theoretical reflection. In what follows, we explore four areas where discussion and research in the field needs to advance: temporal sensitivity and sequencing; the pace of change; periodization; and explaining change - noting some possible solutions and exemplary studies. 


\section{Temporal sensitivity and sequencing}

Research in the social sciences has demonstrated that timing and sequence matter a great deal in social and political development. Advances in event history analysis (e.g., Allinson 1984; Blossfeld \& Rohwer 2002), sought to address the challenge of dealing timevarying variables, adapted traditional methods (including regression) as well as developed new software tools. Some of these solutions could be applied in media and communication research. In historical sociology, a broader range of epistemological and methodological challenges of researching change over time has been considered. A key reference in this area is Abbott's (2001) analysis of temporality in social sciences, which should feature prominently in any attempts to develop more temporally sensitive research in communication, along with the literature on sequence analysis (Blanchard, Bühlman \& Gauthier, 2014; Pierson, 2004) and path dependency (Mahoney 2000). While drawing on both qualitative and quantitative methods, this literature shares the belief in the centrality of sequence in explaining temporal phenomena, and pays particular attention to how events are shaped by the temporal order in which they occur. For scholars sharing this approach, social reality occurs in sequences of actions (or events) associated with specific actors and located within constraining or enabling structures in particular social places and at particular times (Abbott 2001, p. 183).

These debates have so far attracted little attention among communication and media scholars, and this is evident also in our sample. Some studies, for instance, show a surprising lack of temporal sensitivity, with sampling over time seemingly only a way to increase the size of a data set, with little consideration for how the material under study may have changed over time (e.g., Dunaway \& Stein 2013; Richey \& Taylor, 2012). Temporal sensitivity is perhaps most developed in trend mapping exercises. Here event order is central. For studies like Chakravartty's (2004) exploration of national telecoms policy development in India, or Lisosky’s (2001) study of children's television policy over time, the sequence of events is a central part of the explanatory narrative. Policy actors respond to external developments in the environment in a particular order, which is central to explaining the outcomes in each case. However, even in such studies the importance of sequencing remains largely implicit. This limits the ability to extrapolate patterns and to use these as a basis for 
interpretation. The tendency to focus on a single country imposes limitations as well. A comparative cross-national analysis of sequencing in national media policy development, for instance, could be used to establish how the impact of a new policy varies depending on preexisting media infrastructures, political trajectories, or other time-bound factors. Traditions of research rooted in New Institutionalism could be helpful here, and serve to analyze pathdependency in the context of communication and media, as suggested by Bannerman and Haggart (2015). Temporally sensitive cross-national analysis could also help avoid the Galton problem in comparative research, and reveal the extent to which cross-national commonalities are due to borrowing or common descent. Sequence analysis could be applied also in single-country studies; by analogy with the use of sequence analysis in life course research (Blanchard et al. 2014) researchers could adapt sequence analysis for investigating media effects over time, or for understanding how individual media use is shaped by the changing media ecology over a life time.

\section{Pace of change}

Temporal sensitivity also involves paying attention to the pace of change. To start with, this involves acknowledging that social process move at different paces and may take a very long time to evolve. As Abbot (2001, p. 46) puts it: 'events of equivalent causal importance just don’t always take the same amount of time to happen.' This creates a problem for research that spans a limited amount of time; how sure can we be that the causes identified are not merely superficial triggers that rely on deeper factors stretching beyond out temporal frame? A good example of a study that demonstrates this problem is Carmines and Stimson's (1989) study of the evolution of the issue of race in American politics over almost fifty years, which shows that this issue developed through a process of gradual but cumulative change which only becomes apparent when studied over a longer period of time. In communication research, Putnam's (2000) much debated argument about a causal link between declining social capital and television likewise relies on evidence drawn from over half a century. Despite its drawbacks, Putnam's work offers a good example of the potential benefits of such research, but also reminds us of the need for more explicit theorizing and methodological reflection when approaching slow-moving processes, including the consideration of issues such as causal chains and structural determination. 
A related issue of concern is the shifting pace of change; is the pace homogeneous over time, or does it accelerate and decelerate, forming 'eventful' periods followed by periods in which few changes occur (Sewell 1996)? These issues do receive some acknowledgment in our sample, as several studies focus on turning points. However, the sample as a whole rarely engaged with wider debates on this topic. There are some notable exceptions; for instance, Clayman et al.'s (2010) explanation of the growth of aggressive presidential journalism in the US from the 1970s draws on the punctuated equilibrium model, which envisages change as an alteration between longer periods of incremental change, and brief periods of rapid change. This example suggests that communication scholars could profit from engaging more closely with broader literature about the pace of change in political science, but also in history, science and technology studies, and organizational and policy studies (Gersick 1991, Levinthal 1998, Jones \& Baumgartner, 2012).

\section{Periodization}

Periodization (sometimes referred to as phases, see Schulz, 2014) is, either explicitly or implicitly, rooted in in assumptions about the nature of the world, and reflects our analytical priorities (Gerhard, 1965, Green, 1995). From this perspective, it is perhaps understandable that periodizations in our sample use developments in the media as the basis for dividing a time line (in total, 11 articles do so). In most cases, however, the criteria used to distinguish between periods are not sufficiently clear, and lack an explicit justification. Indeed, periodization is often used as a seemingly neutral instrument for organizing historical materials and narrating change. Yet, the division of a time line into periods inevitably carries with it assumptions about the nature of change, and even about the nature of causal relationships driving change. If we are to advance our understanding of change in the media, it is necessary to make these assumptions explicit. For instance, periodizations in our sample were overly media-centric, which was not always justified. Unless we assume that the change we are interested in is driven by the media, media-centered periodizations should be at the very least weighed against alternative periodizations established in other disciplines. Such weighing of alternatives will also force us to question our understanding of the relationship between media change on the one hand, and political, economic or cultural change on the other hand. One exemplary study that does offer a more explicit reflection on the nature of 
the periodization used is Blumler and Kavanagh's (1999) account of the three stages of political communication. Each stage is linked to key changes in society and media, and relies on a clear understanding of causal patterns. For another example, see Bennett and Iyengar's (2008) discussion of the new era of minimal effects.

Another pertinent question related to periodization is its geographical scope: should periodization be based solely on developments in the country/countries under study or should we seek to develop a periodization capable of capturing developments world-wide (Green, 1995)? Given the global reach of communication technologies and the porousness of national boundaries, a globally applicable periodization would make more sense, yet if we are to avoid the pitfalls of ethnocentrism, such an endeavor would need to be accompanied by an understanding of how the different local developments of communication have become interconnected over time, and how these interconnections have affected the sequencing of change in each locale.

\section{Explaining Change}

The studies in our sample were often limited to describing change; only around a third of the sample sought to explicate it in some manner. This was particularly true for trend mapping exercises, especially those focused on production. Despite a relatively high level of temporal sensitivity, explanation in such studies relied almost entirely on describing the processes of change, and taking that as evidence of causation. For example, Chalaby (2012) draws on a history of television formats to explain the emergence of global super-formats in the 1990s, while Falicov's (2000) study of Argentina's blockbuster movies details the influence of government policies on the national film industry (see also Chakravartty, 2004). There is clearly room here for greater methodological and conceptual sophistication. To this end, communication and media scholars could usefully draw on qualitative case study methods developed for the analysis of complex causality, such as pattern matching, process tracing, causal narrative, counterfactual analysis and systematic case comparisons (Bennett \& Elman 2006; Capoccia \& Kelemen 2007).

It is with trend mapping, textual analyses and temporal comparisons that we begin to see more frequent and concerted attempts at explanation rather than solely description. 
However, these studies are virtually entirely reliant on quantitative methods with regression analysis being the most common. For many authors, the limits of regression for analyzing time series data was overlooked (e.g., Atkinson et al., 2014; Webster, 2005). Others reverted to temporally sensitive description to explain outcomes (Kepplinger, 2002), while a few employed techniques designed for time series data analysis, such as Granger causality tests or VAR (vector autoregression) (Groshek, 2011; Lee 2014). A range of other statistical methods designed to analyze time varying covariates (used widely in the social sciences) could also be applied, such as event history modelling (see Box-Steffensmeier \& Jones, 2004).

While most studies in our sample were concerned with explaining the impact of external factors on communication and media, there are also some that focus on the media as an agent of change (e.g., Davidson, 2012; Roy, 2011). However, it is important to note that regardless of the conceptual framework employed, articles concerned with media as the cause of change lacked a reflection on the nature of the causal relationship investigated. Just as changes in the media can rarely be explained by a single cause, care also needs to be exercised in attributing broad social change to the media alone. All too often, studies in this category fail to fully consider causal complexity, and offer an overly media-centered explanation (see Deacon \& Stanyer, 2014).

We should also note while all research aimed at explanation requires a longitudinal design, because causes must precede effects, what often happens in explanatory research is that it proceeds without much awareness of the nature of causality as a temporal phenomenon, in which the particular sequencing of causes may play a key role in determining effects. Indeed, the sequencing of causes and effects is often of no interest, suggesting that such explanatory research treats time as completely neutral, rather than acknowledging it as an object of interest in its own right.

\section{Conclusion}

This review is focused on a set number of journals, and while we feel they are representative of the field up to a point it is no substitute for a full blown review. That said, it provides a first attempt, as far as we know, to map how the field examines change over time. Future studies might want to expand the review, identify other approaches beyond the three identified here, or build on our work to address more specific challenges of temporal research. 
It is quite possible that the relevant debate is taking place in monographs and specialist journals not covered in our overview. We hope that this piece will prompt colleagues working in such specialist fields and those outside to engage with the issues raised here.

Indeed, this article is envisaged as a first step of a longer process leading towards a more conceptually and methodologically mature approach to temporal change. To achieve this, our field needs to engage in a broad conversation about the best ways of approaching change, one that will bring together specialists from different backgrounds. What we found particularly striking when conducting the literature review was precisely the almost complete absence of debate among communication and media scholars interested in studying longitudinal change outside special issues. There was little awareness of cognate studies in the field, and little reference to common methodological challenges or problems experienced. We hope that our article made some headway in this direction, and can serve as a reference point for future discussion.

Three key lessons emerge from our overview, which should be noted in subsequent discussions. First, a temporally sensitive approach can be both qualitative and quantitative, and although each brings its own specific challenges, it is important that our discussion of temporal change spans traditional divisions between quantitative and qualitative research. Such a bridging exercise makes even more sense in light of the fact that qualitative and quantitative approaches seem to offer complementary strengths: as evident from our overview, qualitative trend mapping studies typically displayed a high level of temporal sensitivity, but lacked in methodological sophistication, while quantitative studies fared better in terms of methodological rigor yet sometimes lacked an appreciation of the temporal nature of data. Second, audience research seems to be a particularly underdeveloped sub-set of research on temporal change, and deserves special attention. A key obstacle here is access; while audience data has been collected by a number of bodies over a long span of time, it is typically stored in archives that are difficult to access (for instance, broadcasting archives) and in danger of being lost as limitations on storage capacity push more organizations to discard archival paperwork without digitizing it. If we are serious about advancing our understanding of temporal change in communication, we should do more to help preserve such audience data and make it more accessible for researchers. Third, apart from sustaining a debate about researching temporal change among communication and media researchers 
themselves, we also need to speak to colleagues from other disciplines, especially those with a longer tradition of tackling the challenges of researching change over time.

\section{References}

Abbott, A. (2001). Time Matters: On Theory and Method. Chicago: University of Chicago Press.

Abildgaard, M.S. (2014). Sometimes I think it is hell to be a girl: a longitudinal study of the rise of confessional radio. Media Culture \& Society, 37(2), 1-19.

Allinson, P.D. (1984). Event History Analysis: Regression for Longitudinal Event Data. London: Sage.

Althaus, S.I., Swigger, N., Chernykh, S., Hendry, D.J., Wals, S.C. \& Tiwald, C. (2014). Uplifting Manhood to Wonderful Heights? News Coverage of the Human Costs of Military Conflict From World War I to Gulf War Two. Political Communication, 31(2), 193-217.

Atkinson, L.M., Lovett, J. \& Baumgartner, F.R. (2014). Measuring the Media Agenda, Political Communication, 31(2), 355-380.

Aubrey, J.S. (2006). Effects of Sexually Objectifying Media on Self-Objectification and Body Surveillance in Undergraduates: Results of a 2-YearPanel Study. Journal of Communication, 56(2), 366-386.

Balmas, M. \& Sheafer, T. (2013). Leaders First, Countries After: Mediated Political Personalization in the International Arena. Journal of Communication, 63(3), 454-475.

Bannerman, S. \& Haggart, B. (2015). Historical Institutionalism in Communication Studies. Communication Theory, 25(1), 1-22.

Bennett, W.L., and \& Iyengar, S. (2008). A New Era of Minimal Effects? The Changing Foundations of Political Communication, Journal of Communication, 58(4), 707-731.

Benoit, W.L., Blaney, J.R., \& Pier, P.M. (2000). Acclaiming, Attacking, and Defending: A Functional Analysis of U.S. Nominating Convention Keynote Speeches. Political Communication, 17(1), 61-84. 
Blanchard, P., Bühlman, F., \& Gauthier, J.-A. (Eds.) (2014). Advances in Sequence Analysis: Theory, Method, Applications. Heidelberg: Springer.

Blossfeld, H.P., \& Rohwer, G. (2002). Techniques of Event History Modelling: New Approaches to Causal Analysis. Mahwah, NJ: Lawrence Erlbaum Associates.

Blumler, J., and Kavanagh, D. (1999). The Third Age of Political Communication: Influences and Features. Political Communication, 16(3), 209-230. DOI: 10.1080/105846099198596

Box-Steffensmeier, J.M., \& Jones, B.S. (2004). Event History Modelling: a Guide for Social Scientists. New York: Cambridge University Press.

Butsch, R. (2000). The Making of American Audiences: From Stage to television, 1750-1990. Cambridge: Cambridge University Press.

Callaghan, K., \& Schnell, F. (2001). Assessing the Democratic Debate: How the News Media Frame Elite Policy Discourse. Political Communication, 18(2), 183-213.

Capoccia, G., \& Kelemen, R.D. (2007). The Study of Critical Junctures: Theory, Narrative and Counterfactuals in Historical Institutionalism. World Politics, 59(3), 341-369.

Chakravartty, P. (2004). Telecom, national development and the Indian state: a postcolonial critique. Media, Culture \& Society, 26(2), 227-249.

Chalaby, J.K. (2012). At the origin of a global industry: The TV format trade as an AngloAmerican invention. Media, Culture \& Society, 34(1), 36-52.

Cho, Y. (2009). Unfolding sporting nationalism in South Korean media representations of the 1968, 1984 and 2000 Olympics. Media, Culture \& Society 31(3), 347-364.

Chung, J.E. (2011). Mapping International Film Trade: Network Analysis of International Film Trade between 1996 and 2004. Journal of Communication, 61(4), 618-640.

Clayman, S.E., Elliott, M.N., Heritage, J., \& Beckett, M.K. (2010). A Watershed in White House Journalism: Explaining the Post-1968 Rise of Aggressive Presidential News. Political Communication, 27(3), 229-247.

Coe, K. \& Domke, D. (2006). Petitioners or Prophets? Presidential Discourse, God, and the Ascendancy of Religious Conservatives. Journal of Communication, 56(2), 309-330. DOI: 
Coe, K., Domke, D., Graham, E.S., John, S L., \& Pickard, V.W. (2004). No Shades of Gray:

The Binary Discourse of George W. Bush and an Echoing Press. Journal of Communication, 54(2), 234-252.

Collier, D. \& Collier, R.B. (1991). Shaping the Political Arena: Critical Junctures, The Labour Movement, and Regime Dynamics in Latin America. Princeton, NJ: Princeton University Press.

Corner, J. (2003). Finding Data, Reading Patterns, Telling Stories: Issues in the Historiography of Television. Media, Society \& Culture, 25(2), 273-280.

D’Arma, A. (2009). Broadcasting policy in Italy’s 'Second Republic': national politics and European influences. Media, Culture \& Society, 31(5), 769-786.

Davidson, R. (2012). The emergence of popular personal finance magazines and the risk shift in American society. Media, Culture \& Society, 34(1), 3-20.

Deacon, D. and Stanyer, J. (2014). Mediatization: Key concept or conceptual bandwagon? Media, Culture \& Society, 36(7), 1032-1044.

de Zúñiga, H.G., Molyneux, L., \& Zheng, P. (2014). Social Media, Political Expression, and Political Participation: Panel Analysis of Lagged and Concurrent Relationships. Journal of Communication, 64(4), 612-634.

Domke, D. (2001). The Press, Race Relations, and Social Change. Journal of Communication, 51(2), 317-344.

Dunaway, J. \& Stein, RM. (2013). Early Voting and Campaign News Coverage. Political Communication, 30(2), 278-296.

Gerhard, D. (1956). Periodization in European History. The American Historical Review, 61(4), 900-913.

Gersick, C.J.G. (1991). Revolutionary Change Theories: A Multilevel Exploration of the Punctuated Equilibrium Paradigm. Academy of Management Review, 16(1), 10-36. 
Glevarec, H., \& Pinet, M. (2008) From liberalization to fragmentation: a sociology of French radio audiences since the 1990s and the consequences for cultural industries theory. Media, Culture \& Society, 30(2), 215-238.

Green, W.A. (1995). Periodizing World History. History and Theory, 34(2), 99-111.

Groshek, J. (2011). Media, Instability, and Democracy: Examining the Granger-Causal Relationships of 122 Countries from 1946 to 2003. Journal of Communication, 61(6), 11611182.

Hopmann, D.N. \& Strömbäck, J. (2010). The rise of the media punditocracy? Journalists and media pundits in Danish election news 1994-2007. Media, Culture \& Society, 32(6), 943960.

Jin, D.Y. (2008). Neoliberal restructuring of the global communication system: mergers and acquisitions. Media, Culture \& Society, 30(3), 357-373

Jones, B.D. \& Baumgartner, F. (2012). From There to Here: Punctuated Equilibrium to the General Punctuation Thesis to a Theory of Government Information Processing. The Policy Studies Journal, 40(1), 1-19.

Johnston, A. \& Lee Kaid, L. (2002). Image Ads and Issue Ads in US Presidential Advertising: Using Video Style to Explore Stylistic Differences in Televised Political Ads from 1952 to 2000. Journal of Communication, 52(2), 281-300.

Kepplinger, H.M. (2002). The Mediatization of Politics: Theory and Data. Journal of Communication, 52(4), 972-986.

Levinthal, D.A. (1998). The Slow Pace of Rapid Technological Change: Gradualism and Punctuation in Technological Change. Industrial and Corporate Change, 7(2), 217-246.

Leye, V. (2009). UNESCO’s communication policies as discourse: how change, human development and knowledge relate to communication. Media, Culture \& Society, 31(6), 939956.

Lundby, K. (ed.) (2009). Mediatization: Concept, Changes, Consequences. Bern: Peter Lang. 
Mahoney, J. (2000). Path Dependence in Historical Sociology, Theory and Society, 29(4): 507-548.

Matthes, J. \& Schemer, C. (2012). Diachronic Framing Effects in Competitive Opinion Environments. Political Communication, 29(3), 319-339

Mauersberger, C. (2012). To be prepared when the time has come: Argentina's new media regulation and the social movement for democratizing broadcasting. Media, Culture \& Society, 34(5), 588-605.

Mihelj, S., \& Bourdon, J. (2015). Historicizing Audiences (special issue), European Journal of Communication, 30(1), 3-97.

Papathanassopoulos, S. (2000). Election Campaigning in the Television Age: The Case of Contemporary Greece. Political Communication, 17(1), 47-60.

Peleg, A. \& Bogoch, B. (2012). Removing Justitia's blindfold: the mediatization of law in Israel. Media, Culture \& Society, 34(8), 961-978.

Pickard, V. (2011). The battle over the FCC Blue Book: determining the role of broadcast media in a democratic society, 1945-8. Media, Culture \& Society, 33(2), 171-191.

Pierson, P. (2004). Politics in Time: History, Institutions and Social Analysis. Princeton, NJ: Princeton University Press.

Rawan, S.M. (2002). Modern Mass Media and Traditional Communication in Afghanistan, Political Communication. 19(2), 155-170

Rojecki, A. (2009). Political culture and disaster response: the Great Floods of 1927 and 2005. Media, Culture \& Society, 31(6), 957-976.

Romer, D., Jamieson, K H., \& Aday, S. (2003). Television News and the Cultivation of Fear of Crime. Journal of Communication, 53(1), 88-104.

Roy, S. (2011). Television news and democratic change in India. Media, Culture \& Society, 33(5), 761-777.

Ryfe, D.M. (2001). History and Political Communication: An Introduction. Political Communication, 18(4), 407-420. 
Ryfe, D.M. (2006) Guest Editor's Introduction: New Institutionalism and the News. Political Communication, 23(2), 135-144.

Schulz, W. (2014). Political communication in Long-Term Perspective. In C. Reinemann (Ed.) Political Communication. (pp 63-85) Berlin: de Gruyter Mouton.

Sewell, W.H. (1996). Three Temporalities: Toward an Eventful Sociology. In T. McDonald (Ed.), The Historic Turn in Human Sciences (pp. 245-280) Ann Arbor: University of Michigan Press.

Vancour, S. (2009). Popularizing the classics: radio’s role in the American music appreciation movement, 1922-34. Media, Culture \& Society, 31(2), 289-307.

Volz, Y.Z. (2007). Going public through writing: women journalists and gendered journalistic space in China, 1890s-1920s. Media, Culture \& Society, 29(3), 469-489.

Watson, I. (2002). Irish-language broadcasting: history, ideology and Identity. Media, Culture \& Society, 24(6), 739-757.

Webster, J.G. (2005). Beneath the Veneer of Fragmentation: Television Audience Polarization in a Multichannel World. Journal of Communication, 55(2), 366-382. 
Table 1: A typology of research articles on change over time in three communication and media journals, 2000-2014 (number of articles)

\begin{tabular}{|c|c|c|c|c|c|}
\hline & \multicolumn{4}{|c|}{ Approaches to change } \\
\hline & & Trend mapping & $\begin{array}{c}\text { Temporal } \\
\text { comparison }\end{array}$ & Turning points & Total \\
\hline \multirow{3}{*}{ 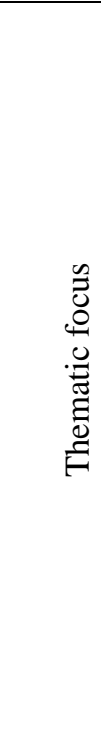 } & $\begin{array}{l}\text { Production(Examinations } \\
\text { of: campaigning practices, } \\
\text { media systems, forms of } \\
\text { broadcasting, } \\
\text { organizations, industries, } \\
\text { policy, professions, } \\
\text { technologies) }\end{array}$ & $\begin{array}{c}54 \\
\text { (JoC 5; } \\
\text { MCS 45; } \\
\text { Pol Com 4) }\end{array}$ & $\begin{array}{c}5 \\
\text { (JoC 2; } \\
\text { MCS 2; } \\
\text { Pol Com 1) }\end{array}$ & $\begin{array}{c}2 \\
\text { (JoC 0; } \\
\text { MCS 2; } \\
\text { Pol Com 0) }\end{array}$ & 61 \\
\hline & $\begin{array}{l}\text { Text (Examinations of: } \\
\text { agendas, bias, content } \\
\text { styles, discourses, } \\
\text { emotions, frames, } \\
\text { memories, soundbites, } \\
\text { representations, .) }\end{array}$ & $\begin{array}{c}46 \\
\text { (JoC 18; } \\
\text { MCS 17; } \\
\text { Pol Com 9) }\end{array}$ & $\begin{array}{c}14 \\
\text { (JoC 5; } \\
\text { MCS 3; } \\
\text { Pol Com 6) }\end{array}$ & $\begin{array}{c}2 \\
\text { (JoC1; } \\
\text { MCS 0; } \\
\text { Pol Com 1) }\end{array}$ & 62 \\
\hline & $\begin{array}{l}\text { Audience (Examinations } \\
\text { of: audience attitudes, } \\
\text { opinions,, participation, } \\
\text { media effects) }\end{array}$ & $\begin{array}{c}7 \\
\text { (JoC 3; } \\
\text { MCS 2; } \\
\text { Pol Com 2) }\end{array}$ & $\begin{array}{c}7 \\
\text { (JoC 4; } \\
\text { MCS 2; } \\
\text { Pol Com 1) }\end{array}$ & $\begin{array}{c}1 \\
\text { (JoC 0; } \\
\text { MCS 1; } \\
\text { Pol Com 0) }\end{array}$ & 15 \\
\hline Total & & 107 & 26 & 5 & $138 *$ \\
\hline
\end{tabular}

*The table excludes the 8 theoretical articles, the 1 methodological article, and the 4 research articles that aggregated time series data as if gathered from the same time point.

Table 2: The time span of selected studies (number of articles)

\begin{tabular}{|l|l|l|l|l|}
\hline Time span (years) & Trend mapping & $\begin{array}{l}\text { Temporal } \\
\text { comparison }\end{array}$ & Turning points & Total \\
\hline $0-9$ & 21 & 10 & 2 & 33 \\
\hline $10-19$ & 23 & 5 & 1 & 29 \\
\hline $20-29$ & 18 & 1 & 0 & 19 \\
\hline $30-39$ & 12 & 3 & 0 & 15 \\
\hline $40-49$ & 10 & 1 & 1 & 12 \\
\hline $50-59$ & 7 & 0 & 0 & 7 \\
\hline $60-69$ & 4 & 0 & 0 & 4 \\
\hline $70-79$ & 3 & 2 & 1 & 6 \\
\hline $80-89$ & 2 & 0 & 0 & 2 \\
\hline $90-99$ & 1 & 1 & 0 & 2 \\
\hline $100+$ & 6 & 3 & 0 & 9 \\
\hline Total & 107 & 26 & 5 & 138 \\
\hline
\end{tabular}

